\title{
Functional neuroimaging in Hashimoto's encephalitis: a physiopathological imaging?
}

\author{
Jordi Fuertes • Amparo García-Burillo • \\ Joan Castell-Conesa $\cdot$ Isabel Roca
}

Received: 28 October 2008 / Accepted: 5 December 2008 /Published online: 21 January 2009

(C) Springer-Verlag 2009

Hashimoto's encephalitis, a probably misdiagnosed disease, is also known as steroid-responsive encephalopathy associated with autoimmune thyroiditis [1]. We present a 79-yearold female with rapidly progressive dementia, serum values for hypothyroidism and clinical suspicion of the disease. She underwent a ${ }^{99} \mathrm{~m}$ Tc-ECD brain perfusion single photon emission computed tomography (SPECT) scan, which showed global and severe hypoperfusion of the whole brain cortex (upper row). Anatomical neuroimaging (CT, MRI) was near-normal, showing only mild age-related cortical atrophy. After 8 months of corticoid therapy, the patient experienced a progressive clinical recovery of superior functions, and a control SPECT scan showed normal brain perfusion (lower row). The hypoperfusion pattern found in this patient might have been related to a vasculitic mechanism as has been reported in this kind of encephalopathy $[2,3]$.

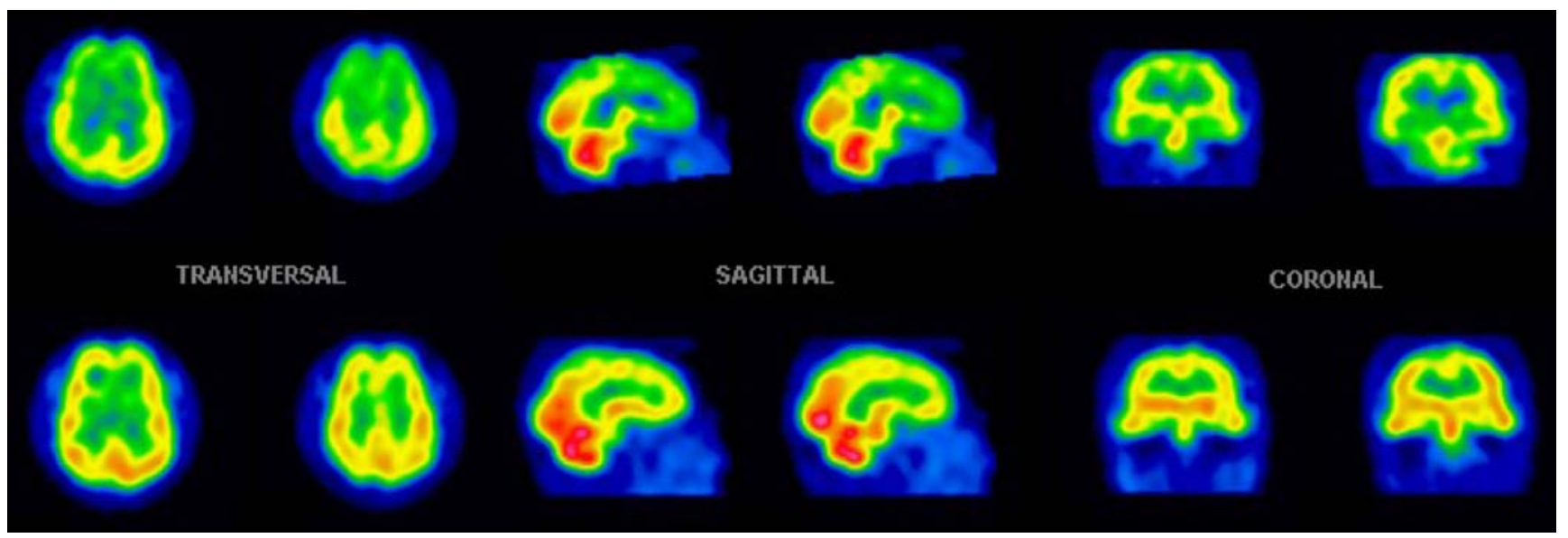

J. Fuertes $(\bowtie) \cdot$ A. García-Burillo $\cdot$ J. Castell-Conesa $\cdot$ I. Roca Department of Nuclear Medicine, Gamma Delfos,

Av. Vallacarca 151,

08023 Barcelona, Spain

e-mail: jfm35709@yahoo.es

\section{References}

1. Castillo P, Woodruff B, Caselli R, Vernino S, Lucchinetti C, Swanson J, et al. Steroid-responsive encephalopathy associated with autoimmune thyroiditis. Arch Neurol 2006;63(2):197-202.

2. Mocellin R, Walterfang M, Velakoulis D. Hashimoto's encephalopathy: epidemiology, pathogenesis and management. CNS Drugs 2007;21(10):799-811.

3. Tamagno G, Federspil G, Murialdo G. Clinical and diagnostic aspects of encephalopathy associated with autoimmune thyroid disease (or Hashimoto's encephalopathy). Intern Emerg Med 2006;1(1):15-23. 